\title{
POÉTICA DO BANAL E SUA CONTRIBUIÇÃO AOS PROCESSOS E PRÁTICAS ARTÍSTICOS DOCENTES
}

Thiago Heinemann Rodeghiero*

\begin{abstract}
RESUMO: Este artigo tem como intenção tratar e pensar a contribuição dos processos artísticos às práticas docentes. Nas fronteiras borradas da arte contemporânea, filosofia e educação, delineia-se num plano de consistência que tensiona novas formas de fazer professoral. Recorrerá aos processos artísticos do pesquisador (poética do banal) para pensar meios, trajetos e forças que façam vetor às práxis pedagógicas. Busca nas filosofias da diferença de Gilles Deleuze e Félix Guattari um pensamento que prolifere como erva daninha e encontros que deem potência de agir. Tensionando os vazamentos de práticas educacionais baseadas em modelos estruturados, põe em movimento uma artistagem docente e uma formação sensível que buscam, na prática do artista-pesquisador e os artistas referentes Allan Kaprow, Paulo Bruscky e Karina Dias, forças para desenhar novas formas. Justificase por priorizar uma heterogenia dos elementos e matérias que rompem com os modelos hegemônicos e os assujeitamentos dos modelos de professorado para compor o território de pesquisa. Oferece à educação um pensamento calcado na prática de um processo artístico, fazendo e traçando um plano de consistência, desterritorializando as formas definitivas de bom professorado.
\end{abstract}

PALAVRAS-CHAVE: Arte Contemporânea; Educação; Filosofias da Diferença; Práticas Docentes; Poética do Banal.

\section{BANAL POETICS AND ITS CONTRIBUTION TO ARTISTIC TEACHING PROCESSES AND PRACTICES}

\begin{abstract}
This article intends to deal with and think about the contribution of artistic processes to teaching practices. In the blurred frontiers of contemporary art, philosophy and education, it is outlined in a plan of consistency that stresses new ways of performing professorship. The researcher's artistic process will be used (banal poetics) to think of means, paths and forces that make vectors to pedagogical praxis. It searches in the philosophies of difference of Gilles Deleuze and Félix Guattari for a thought that proliferates like weed and encounters that give the power to act. Tensioning the leaks of educational practices based on structured models, it sets in motion a teaching artistry and a sensitive formation that seek, in the practice of the artist-researcher and the referring artists Allan Kaprow, Paulo Bruscky and Karina Dias, forces to design new forms. It is justified for prioritizing a heterogeneity of the elements and materials that break with the hegemonic models of teaching to compose its research territory. It offers to education a thought based on the practice of an artistic process, making and drawing a plan of consistency, deterritorializing the definitive forms of good teaching.
\end{abstract}

KEYWORDS: Contemporary art; Education; Philosophies of Difference; Teaching Practices; Banal Poetics.

\footnotetext{
* Mestre em Educação pelo Programa de Pós-graduação da Universidade Federal de Pelotas; Pesquisador e Técnico em Edição de Imagens da Universidade Federal de Pelotas; thiagoalfa@gmail.com ; http://orcid.org/0000-0001-9706-7903
} 


\section{Introdução}

Este texto tem como intenção tratar e pensar os processos artísticos e práticas docentes engendrados em micropolíticas que têm a banalidade como campo experiencial. No processo de lidar com os espaços e objetos residuais, opera-se uma prática como forma de criar procedimentos e ser afetados pelos encontros que se mostram a partir do movimento. Nas margens disformes da arte contemporânea e da filosofia, desenha um plano de consistência que tensiona os modos de fazer.

Recorrendo à uma produção artística, a Poética do Banal, pensa meios, trajetos e forças que façam vetor às práxis de feitura de trabalhos e de pensamento em arte contemporânea e da educação. Colocando a vazar as práticas de pesquisa, o cotidiano (DIAS, 2015) é experimentado nos processos desta prática artística ao pôr em fluxo os processos sensíveis. Busca-se nos artistas referentes, Allan Kaprow (2003, 2004, 2010), Karina Dias (2011) e Paulo Bruscky (ANJOS, 2004; BRITO, 2011), formas de priorizar os encontros, compondo com as filosofias pós-estruturalistas e da diferença um pensamento que prolifere como erva daninha (DELEUZE; GUATTARI, 2011), dando potência de agir. Assim, ao dispensar esses modos prontos, oferece à educação um pensamento calcado na prática de um processo artístico.

Justificado por priorizar uma heterogenia dos elementos e de matérias que rompem com o eu centrado do humanismo, compõe um território de pesquisa que coloque o cotidiano como possibilidade de reinvenção pelas margens e pelas periferias dos territórios em deslocamento e deambulações. Assim, a Poética do Banal é posta como vetor para pensar a possibilidade de proliferar as criações oriundas dos encontros por ela posta. Fugir dos dogmatismos da imagem é criar formas de vida. A Poética do Banal não representa a vida, mas é o meio pelo qual a vida pede passagem. Uma ética produtora de imagens que escapam do dogmatismo, a qual está calcada na necessidade de introduzir algo que faça pensar, sentir e vazar os trabalhos. A banalidade faz com que as subjetividades sofram desgastes e se cansem, trazendo uma "diminuição da potência da condição de vivente" (ROLNIK, 2018, p. 75) aos corpos e lhe roube sua força pulsional. Não reduzindo a subjetividade ao sujeito, este artigo propõe pensar o saber ecosófico da banalidade, uma intuição que dá margens às potências embrionárias (ROLNIK, 2018, p. 75) pela arte.

Oferecendo um pensamento calcado na prática de um processo artístico, se faz e se traça um plano de consistência que coloca a "elaborar um material cada vez mais rico, cada vez mais consistente, apto a partir daí a captar forças cada vez mais intensas" (DELEUZE; GUATTARI, 2012a, p. 149). A prática vem, desta forma, como uma maneira de retirar os privilégios da observação passiva e "indicar a profundeza que a habita, que a move" (DIDI-HUBERMAN, 2010, p. 33), dando outras potências capazes de atribuir sentidos e não significados. Nas ecologias, esta prática encontrará modos de "captura, 
de descentramento, de multiplicação dos antagonismos e de processos de singularização que surgem [d]as novas problemáticas ecológicas" (GUATTARI, 2012, p. 14) e fará composição com a arte.

Neste plano, numa prática artística é pensada no investimento da processualidade e potência do próprio fazer como força motriz. Ainda, os trabalhos artísticos (a Poética do Banal e suas séries) inventam um lugar comum e fazem paisagens que, ao claudicar, produzem perturbação que deixam de ser evidente seu significado (CAUQUELIN, 2007), fugindo do bom gosto e satisfação que provocam "um juízo a partir de critérios explícitos” (p. 123). Usando os deslocamentos e deambulações como procedimento de produção e experimentação dos territórios, intui-se um "ponto de vista estético-experiencial” (CARERI, 2013, p. 159). A imagem, então, é movimentada conforme o território habitado pela poética é transformado, produzindo potência-devires que a libertem de sua realidade por "operações que determinam a natureza artística do que vemos" (RANCIÈRE, 2012, p. 15), de sua rigidez e de seu dogmatismo.

Calca-se aqui, como maneira de fazer poéticas visuais na contemporaneidade, a não aderência a linguagens artísticas específicas, pois trata-se de pensar os procedimentos como forma de fazer artístico. Este modo não assume uma ordem anterior pré-estabelecida, mas segue os rumores de como os signos de processualidade se mostram e se captam, formando, assim, maneiras singulares de colocar em movimento o próprio ato poético. Dispensar as linguagens não quer dizer abandonar as práticas artísticas, mas, sim, inventar pela precariedade de que este método assume uma pulsão do "se faz fazendo" em composição com o próprio acompanhamento processual.

O método para este artigo se faz aos moldes de uma cartografia (DELEUZE; GUATTARI, 2010; 2011), superpondo os elementos e matérias num plano (DELEUZE, 2011), a ser deslocado pelas forças e pelos vetores da arte. Os conceitos abordados farão composição, pois "longe de desenhá-los, ele [o pesquisador em artes] os usa e os trabalha" (LANCRI, 2002, p. 19). O processo da pesquisa visa a “explorar os meios, por trajetos dinâmicos, e traçar o mapa correspondente” (DELEUZE, 2011, p. 83) pelo seu próprio fazer poético.

Dispensando modelos prontos de se fazer pesquisa, a cartografia é invenção pois, sendo um método que permite que novas existências possam vazar, cria subjetividades. Buscando redes de conceitos que proliferem e façam consolidar meios, trajetos e forças, é nas filosofias da diferença que se produzem ritmos que passam pelas transcodificações e, entre as vibrações dos meios, criar um território: um "produto de uma territorialização dos meios e dos ritmos" (DELEUZE; GUATTARI, 2012a, p. 127).

O objetivo é tecer uma experimentação pelos afectos que pedem passagem na processualidade da produção artística, buscando na produção poética, nos textos de artista e nas filosofias da diferença as consistências para esta pesquisa. Ainda, no que diz respeito à poética do banal e às relações entre arte, ecosofia e filosofia, pretendo olhar para a pesquisa enredada nos caminhos de práticas. Logo, chega-se à 
pergunta: como fazer fruir e criar, a partir da sensível micropolítica do desgaste do banal, experimentações poéticas? Esta é a inquietação germe a partir da qual se debruçará nas matérias e se tecerá conexões.

Para tanto, a causa deste texto é encontrar as forças de uma ética micropolítica que dispensem as montagens classificatórias definitivas das macropolíticas. Portanto, a trajetória da pesquisa é calcada na vazão a uma produção artística não moralizante “da percepção, da afecção, da conversa” (DELEUZE; GUATTARI, 2012b, p. 99), da troca, do uso coletivo e da sensibilidade que os processos engendrarão. Acredita-se que fazer arte, produzir imagens e fotografar são movimentos de dar vazão às expressões dos pequenos gestos criadores de sensação. Logo, a hipótese é de que a prática banal é um movimento possível de não cair no empobrecimento ético que cria vidas com subjetividades precárias e destroçadas de suas forças pulsionais e poder pensar assim uma educação do sensível.

Não negando ou sobrepondo o entendimento de que a educação está ligada a uma mecânica de mercado, ao estado e à produção de subjetividades capitalísticas (GUATTARI, 2012), engendra uma necessidade de criar, fazer vazar as estruturas e incluir outras questões a este problema. Pensar em um processo educacional que a processualidade artística esteja "enredada" nos processos de práticas docentes e estabelecer relações entre leitura, invenção, apropriação, escrita e produção de trabalhos artísticos é uma forma de partilha sensível da pesquisa.

\section{Poética e processos artísticos contemporâneos}

Na geografia deste artigo, a Poética do Banal é o cotidiano inventado como maneira de perceber o mundo, uma prática composta em séries: Pequeno Território, Ob.so.les.cên.ci.a e Degradação. Segmentando-as, essas séries são engendradas em sequências diferentes que inventam maneiras de dizer. Seu processo envolveu deambular e conhecer espaços, matérias habituais e rotas comuns como forma de prática artística. Usou-se do caminhar como prática estética (CARERI, 2013) para perambular pelos limites dos territórios conhecidos. Compostos de fotografias, vídeos, desenhos e anotações, os trabalhos deixam emergir a pungência do abandono e têm algo em comum: ocupam-se em operar espaços e objetos residuais; a rotina de trabalho; e o descarte/desuso.

O banal são as imagens dogmáticas do abandono, invisível aos olhos, mas fértil ao pensamento. Sua desterritorialização é feita pela força da arte, inventando um espaço e dando contorno ao esquecimento: o comum que se torna extraordinário na arte contemporânea. Uma composição que não hierarquiza os elementos que constituem, mas os superpõe no território, encontrando forças que os deixem subir à superfície. 


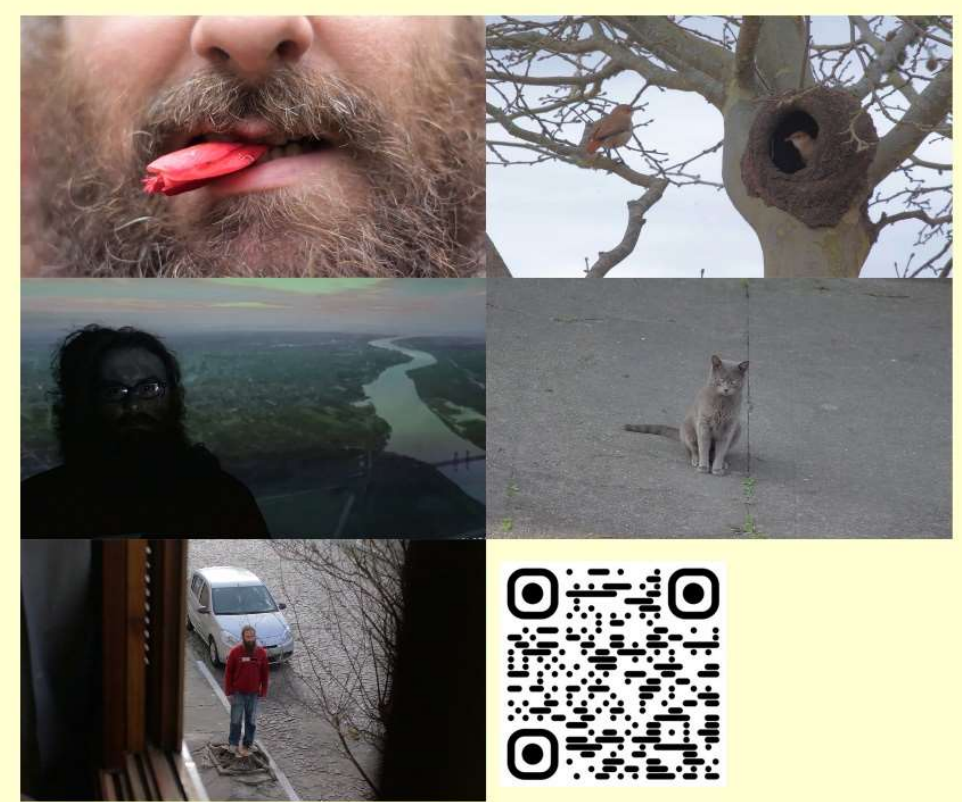

Imagem 1 - Mosaico de frames do vídeo Pequeno Território.

Fonte: Arquivo Pessoal disponível em http://bit.ly/pequenoterritorio

Para a criação da série Pequeno Território (Imagem 1), investiu-se num recorte: um olhar ao que está em volta, em tudo aquilo que surgia como banal. O procedimento foi segmentado em etapas: numa primeira, fez-se uma espécie de produção de um inventário-catálogo, anotações e desenhos que relatam os objetos-lugares e o meio; posteriormente, numa segunda, captaram-se imagens, vídeos e fotos de tudo aquilo que se lançava aos olhos. Nela registram-se alguns recortes de um território já conhecido: o que se vê.

Assim, cria-se um espaço de potência e "uma multiplicidade de pontos de vista que traduzem nossa maneira de ser e estar no mundo” (DIAS, 2011, p. 3773); um cotidiano que surge como forma de ver o próprio fazer artístico na sua pulsão de existência. Uma potência que estava em germe e, circunscrito em séries pelo deambular de um Pequeno Território, traz à tona o olhar para as obsolescências, o descarte e o abandono; localiza vetores para dar mote a lugares fazíveis, brotando por entre as paredes e fissuras que insistem em permanecer invisíveis ao olhar cansado. Composta de fotos, vídeos e anotações, integra os trabalhos da Poética do Banal, retirando as sedimentações, atravessando e criando vazamentos nos processos de artista. Busca, durante a feitura, um território habitável e põe na adjacência vetores nas veredas a serem reveladas pelo caminhante. Recolhendo os elementos, observa a banalidade de um tempo/objeto/território, seguindo o que intui: um exercício diário de [re]existência "para a desorientação e a reorientação dos afetos" (ROLNIK, 2016, p. 68). 


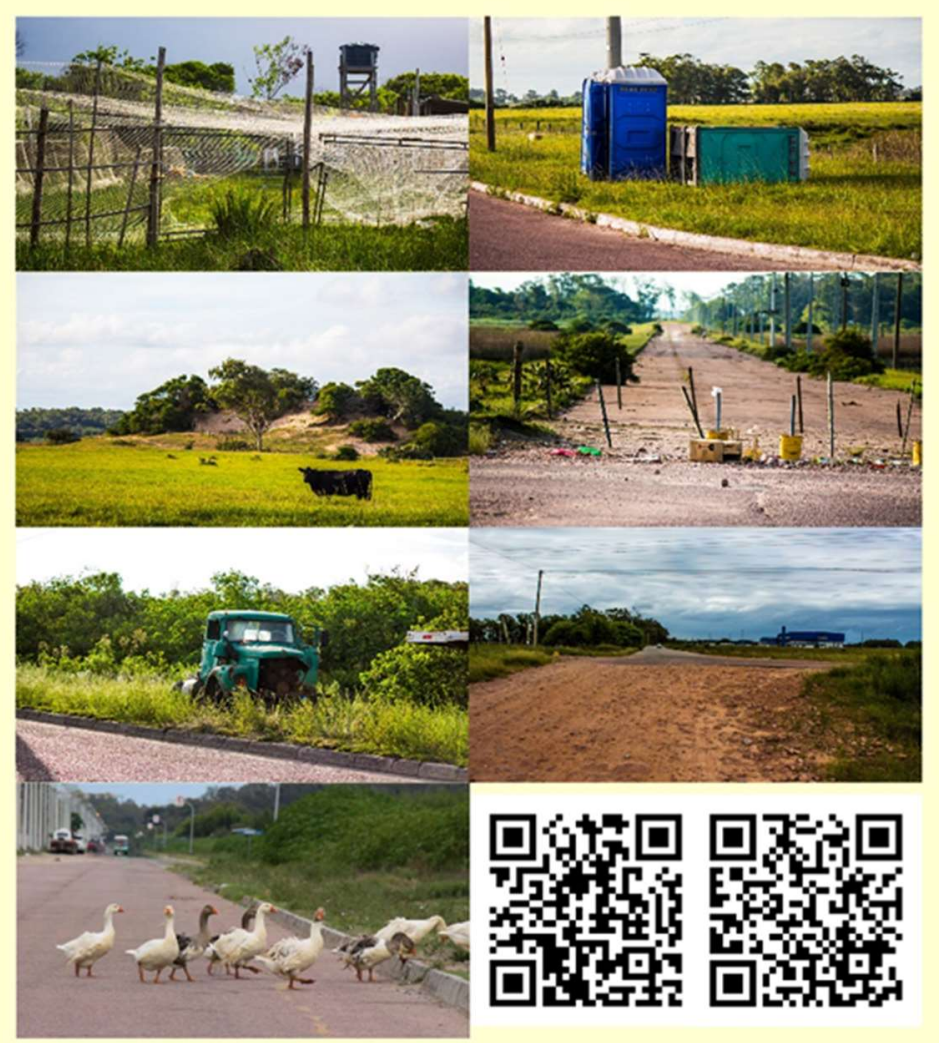

Imagem 2 - Alguns trabalhos da série Ob.so.les.cên.ci.a.

Fonte: Arquivo Pessoal disponível em http://bit.ly/obsole1 e http://bit.ly/obsole2

A série Ob.so.les.cên.ci.a (Imagem 2) capta um perímetro segundo o fazer artístico (deslocamento e deambulação) e superpõe as maneiras de dizer e olhar sobre o território. Ao se passar por um caminho corriqueiro várias vezes, alternam-se os sentidos pela inventividade. O artista Allan Kaprow $(2003 ; 2004)$ é uma referência de processo artístico que se aproxima desta série ao colocar que a anfemiridade dos lugares é o exercício do pensar. Ao invés de perseguir o extraordinário, encontra na banalidade das atividades os fluxos das similitudes com a vida cotidiana que transformam os atos triviais em sensibilidades e potências de sentidos. Construída pelos processos que compõem experiências nos deslocamentos geo-artísticos, orienta-se no meio dos procedimentos de invenção de mundos, encontrando as potências pelas forças banais do cotidiano. Não se recorre a modelos pré-estabelecidos de juízos predeterminados: prefere-se aquilo que não salta aos olhos. Ao perseguir estes encontros, as pistas e os signos surgem e outras maneiras de habitar o espaço ganham consistência. 


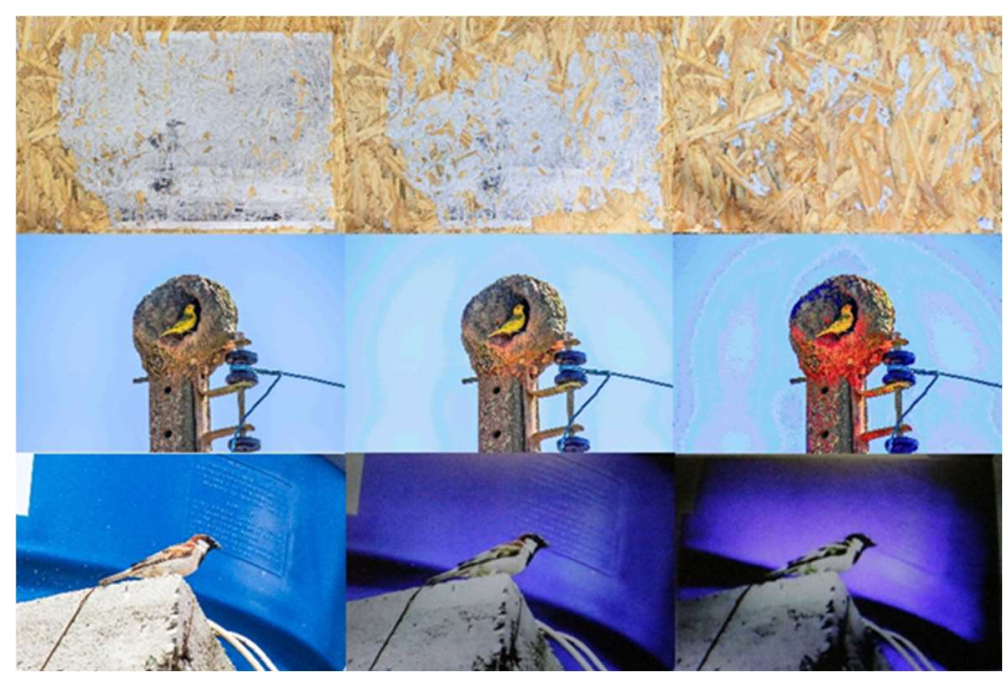

Imagem 3 - Sequência de imagens da série Degradação.

Fonte: Arquivo Pessoal

Degradação (Imagem 3) fala dos desgastes que a imagem sofre. O procedimento se deu em meio à crise sanitária global oriunda da Covid-19, em que a impossibilidade de se deslocar fisicamente pelos locais tensionou maneiras de fazer a banalidade pela reapropriação. Pegaram-se algumas imagens e criou-se uma maneira de desgastá-las analogicamente e digitalmente. As imagens tornam-se resistentes e mantêm-se apesar de algumas tentativas.

Visitou-se o arquivo de imagens e trabalhos que foram feitos durante anos anteriores e os transformou num fluxo para tentar desfazê-los: criou-se outras formas pela força em germe. $\mathrm{O}$ arquivo como banalidade é o que se encontrou do cotidiano, fixando maneiras de acolher as afecções e singularidades. Assim como Paulo Brunsky, o arquivo é rizoma (BRITTO, 2011), pois não classifica e nem homogeneíza, mas prolifera e se multiplica.

As intensidades da prática banal dizem das subjetividades e seus efeitos nas trivialidades de uma micropolítica dos processos artísticos. Trazendo o olhar para o obsoleto, removem-se os códigos de juízo e de moralidade e encastram-se as alternâncias possibilidades de dessignificar as certezas classificatórias da macropolítica (GUATTARI; ROLNIK, 1986). Vivenciando os trajetos sem preestabelecimentos, faz aderência a encontros singulares que retiram a vida lá de onde ela é prisioneira.

Desdobrando-se em novas maneiras de montar-fazer-dizer sobre o ordinário, as séries são concebidas num investimento cotidiano como forma de arte. Os elementos deste território se dispõem em objetos-lugares e, colocados em variação, desterritorializam/movimentam os traçados comuns, operando matérias e substâncias e dando a elas novos sentidos. As imagens que fogem de seu dogmatismo e de modelos de boa imagem transformam e manejam os devires que aderem ao artistacartógrafo, deixando as suas forças repousarem sobre o esquecimento e os lugares de passagem.

As séries da Poética do Banal arranjam territórios que pensam o seu próprio fazer, encontrando nos procedimentos as expressões que constroem os lugares por onde passam. Não se trata de interpretálos; trata-se, antes, de detectar suas trajetórias e processualidades, servindo de indicadores de novos 
universos e de referência e dando a estes movimentos a consistência transformadora de situações cotidianas.

A poética do banal é pensada pelos atos de encontrar e localizar elementos já saturados, fazendo acontecimentos a partir destes. Assumindo um caráter de experimentação, deixa de lado os vetores do extraordinário para criar o sensível e favorecer afectos as matérias pela qual movimenta-se. A sensação é o motriz pela qual encontra a sua força, deixando surgir à superfície suas relações e encontros. Trazendo o que está condicionado e estruturado à tona, esta poética coloca-se em intensidades exploratórias para pensar e produzir arte.

\section{Revisão bibliográfica e método}

O texto pretende fazer uma revisão bibliográfica em escritos e processos de artistas, buscando contribuição nas filosofias da diferença para relacioná-los com a produção poética. Ao modo de uma cartografia, as referências conjuram os artistas, que, a priori, fazem composições com a produção poética. Caros à poética do banal, Allan Kaprow, Karina Dias e Paulo Brunsky, circunscrevem parte do território e o fazem criar outras margens.

O artista estadunidense Kaprow coloca em experimentações do cotidiano as formas de fazer junto arte (KAPROW, 2003; 2004; 2010), investindo em maneiras de colocar o processo a fruir como trabalho artístico. Quando suas atividades (KAPROW, 2010) são inseridas em meios anfêmeros, as tarefas propostas se mesclam com a vida, agenciando com o contexto inserido e ganhando outras formas. A mesma atividade pode ter sensações bem distintas conforme a sua aderência com as situações.

Os Happenings (KAPROW, 2010) são construídos pela variação do comum. As suas listas das atividades cotidianas oferecidas ao público-artista-participante montam suas forças e juntos compõem um processo artístico que se faz coletivamente. Transformando público em atuador do processo-objetoespaço, propõem novos usos e relações a eles. As potências destas ações rasgam a ordem e a organização estabelecida como senso comum da arte; o espectador não é mais um ser passivo, a obra perde seu efeito de sagrado, de intocabilidade e de genialidade artística. Em sua dupla de textos, A educação do an-artista, parte I e II, Kaprow (2003; 2004) propõe a integração de espaço, matérias e pessoas, colocando o espectador envolvido na criação das obras. Ele convoca a arte a criar uma não-arte, uma evocação das atividades sociais comuns. O efeito causado por estas práticas desafia o clube da arte, fazendo-o ganhar alegria em seus encontros.

O banal como força poética é no que a artista e pesquisadora brasileira Karina Dias investe em seu trabalho. O cotidiano é visto como uma experiência paisagística (DIAS, 2011), tornando-se uma tentativa de restituir a transformação perceptiva em eterno movimento e fazendo "o caminho de sempre ganha[r] outro contorno" (DIAS, p. 3772). A artista recorre a uma banalidade para fazê-la ganhar uma "tautologia poética" (DIAS, p. 3772), pois, ao capturar uma paisagem, engendra-se em si mesmo um 
processo sensível e passível de ser afectado pelo envolvimento artista-trabalho-espectador. Logo, o cotidiano é "um conjunto de percursos e situações que se repetem dia após dia, nos pressionando, nos impondo o peso de certa maneira de viver" (DIAS, 2015, p. 4) e de dar voz à banalidade: uma forma de enfrentar essas formas hegemônicas de vida. Ainda, como forma de deambular e ver o banal, Dias nos diz:

A experiência da paisagem no cotidiano se forjaria, então, na junção de uma certa maneira de olhar e dos caminhos percorridos. Ela tomaria forma a partir de detalhes corriqueiros que por serem vistos e (re)vistos continuamente se tornariam invisíveis aos nossos olhos (DIAS, 2015, p. 2).

Os processos dos trabalhos de Paulo Bruscky são verdadeiros labirintos, em que é preciso se inventar maneiras de entrar e sair sem perder o sentido de seu fazer. Em uma obra chamada o atelier como arquivo, o artista aprofunda e inventa, por mais de três décadas, um trabalho que é um "espaço de desclassificação onde as diferenças se anulam” (ANJOS, 2004, p. 275). Seu processo é infindável, encontrando-se sempre em um meio "tal como cartógrafos que percorressem apenas desertos ou labirintos, o lugar incerto que a arte gera e ocupa” (ANJOS, p. 275). O conceito de atelier-arquivo é caro a esta pesquisa, pois é nele que "em um espaço em comum, expandem-se e dialogam com diferentes conteúdos [...], desafiando fronteiras e restrições de qualquer natureza” (BRITTO, 2011, p. 16).

Pensar a produção e a prática deste texto que versa sobre arte é um ato de resistência (DELEUZE; GUATTARI, 2010) e tal faz “apelo a um povo que ainda não existe" (DELEUZE; GUATTARI, 2010, p. 343). Para tanto, na arte contemporânea, sobretudo com artistas que investem no cotidiano como território de ação, o processo é pautado pelo fazer: é uma invenção que produz a fruição do sensível aos seres. Para Deleuze e Guattari, “o objetivo da arte [...] é arrancar o percepto das percepções [...], arrancar o afecto das afecções [...] [e] extrair um bloco de sensações, um puro ser de sensações" (2010, p.197), dando a quem participa de seu processo maneiras de experimentar e sentir. Para tanto, olhar não diz mais de apenas observar, mas de "fechar os olhos para ver quando o ato de ver nos remete, nos abre a um vazio que nos olha, nos concerne e em certo sentido, nos constitui" (DIDIHUBERMAN, 2010, p. 31).

Esta sensibilidade que surge da arte deixa afectar-se, mas isto não quer dizer que é o mesmo que afetar-se, pois “os afectos são precisamente estes devires não humanos do homem” (DELEUZE; GUATTARI, 2010, p. 200), retirando-os do centro do mundo e fazendo-os ser parte deste. Este movimento é desencadeador de devires que "não se imita [...] [pois é] uma zona de vizinhança ou de indiscernibilidade [...] através dos componentes de desterritorialização” (DELEUZE; GUATTARI, 2012, p. 113-114). Tensionados por estas forças, estes agregados sensíveis, que a arte engendra, dão ao homem paisagens não humanas: os motivos revolucionários para colocá-lo em movimento.

Como procedimento de produção de dados, o deslocamento e a deambulação são modos para engendrar processos e poéticas. Para Francesco Careri (2013), é pelas margens que existem lugares, 
surgindo novas maneiras de habitar e viver, e o autor diz que a errância "nas margens do sistema [faz] as transformações [...] mais prováveis e velozes” (CARERI, 2013, p. 158). A errância é a prática pelo qual uma poética que tem a experimentação com forma pode surgir, pois:

É preciso aprender a perder o tempo, a não buscar o caminho mais curto, a deixar-se conduzir pelos eventos, a dirigir-se a estradas impraticáveis onde seja possível "topar", talvez encalhar-se para falar com pessoas que se encontram ou saber deter-se, esquecendo que se deve agir. Saber chegar ao caminhar não intencional, ao caminhar indeterminado (CARERI, 2013, p. 171).

Implicada nos modos intensivos, que dizem respeito às forças que movimentam uma existência, a micropolítica, conceito inventado por Guattari (GUATTARI; ROLNIK, 1986; DELEUZE; GUATTARI, 2012a), a partir de sua experiência com a farmácia, não quer dizer da pequenez política, “mas pela natureza de sua 'massa' - o fluxo de quanta, por sua diferença em relação à linha de segmentos molar" (DELEUZE; GUATTARI, 2012a, p. 105). O autor define que uma macropolítica, uma política molar, se define pela persistência de uma classificação definitiva que diz das representações em composição com uma micropolítica, política molecular, que diz das crenças e dos desejos. Não são opositivas, mas vetores que travam um campo de batalha pela disputa e demarcação política de um espaço-tempo histórico. Enquanto uma macropolítica funda uma história, a micropolítica abre-a e inventa novas segmentalidades. Não se pode cair no juízo de que uma macropolítica seria má e uma micropolítica seria boa, pois, como já alertava Guattari com Deleuze em Mil Platôs (2012a), há de se ter uma prudência a não cair em uma direção indesejável da sobrecodificação pelo medo de perder (ou de se perder), pela clareza do molecular (em querer classificar para dar uma identificação) e pelo poder (que trataria de dar margens empobrecidas às subjetividades).

As imagens tratadas aqui neste texto são operações, tal qual Jacques Rancière (2012, p. 13) diz de Bresson: "são operações que vinculam e desvinculam o visível e sua significação, ou a palavra e seu efeito, que produzem e frustram expectativas". Isto se dá pelo fato de que se produzem sem a necessidade de representar, mas estas se fazem na "ambiguidade das semelhanças e a instabilidade das dessemelhanças, operar uma redisposição local, um rearranjo singular das imagens circulantes" (RANCIÈRE, 2012, p. 34). A maneira pela qual se arranja e se produz o processo de fabricação dessas formas de se fazer ver é da ordem do sensível, diz mais do que afecta do que se substantiva.

Uma micropolítica do fazer artístico se imbrica nas banalidades como matéria ainda disforme, que carece de formas para ser dita. Há uma regra de prudência que orienta essa busca: ir ao encontro de outras formas pulsantes de vida. Para tanto, cria-se uma "força coletiva de criação e cooperação" (ROLNIK, 2018, p. 90) capaz de desidentificar a banalidade, dando outros contornos e forças que proliferem vida. A micropolítica assume um papel ético, de não deixar-se sobrecodificar as matérias que percorre, sem medo de se perder e não classificando antecipadamente as pulsões em germe que se 
experienciam. Uma molecularidade é uma ecologia criadora de resistência não somente ambiental, mas, também, social e mental (GUATTARI, 2012).

Neste percurso estético se problematizam as banalidades através de uma ética ecosófica. Recompondo o olhar e dando consistência às subjetividades destroçadas pelas degradações ambientais, sociais e mentais, na ecosofia é que se encontra força para estabelecer relações entre as várias formas que pulsam na subjetividade dos viventes. A força ambiental então não deve enfrentar sozinha o capital, pois, segundo o autor, os grupos arcaicos que a defendem "não estão de modo algum seguros que continuarão a vencê-la" (GUATTARI, 2012, p. 36) e "a ecologia social deverá trabalhar na reconstrução das relações humanas em todos os níveis" (GUATTARI, 2012, p. 33) para poder dar heterogenia na simultaneidade mental "onde o belo coexiste com o feio, o dentro com o fora, o 'bom objeto' com o mau" (GUATTARI, 2012, p. 38). Cria-se uma cartografia ético-ecológica para deixar pulsar os vetores que compõem agenciamentos potentes o suficiente para dar às margens novas lufadas de existência.

A cartografia como método de pesquisa não tem modelos e ocupa-se em deixar que as intensidades experimentadas ganhem consistência (DELEUZE; GUAT'TARI, 2012b), impulsionando desterritorializações criadoras de novas formas de pensamento acerca da arte contemporânea. Como é um método que se monta fazendo, não há objetos de pesquisa certos, nem dados a serem coletados e sim um processo de produção de subjetividades. Não tendo "o menor racismo de frequência, linguagem ou estilo" (ROLNIK, 2016, p. 65), busca quaisquer elementos que possam vir a compor seus mapas. “Todas as entradas são boas, desde que as saídas sejam múltiplas" (ROLNIK, 2016, p. 65), desde que coloquem os ritmos a criar por entre os meios. Os elementos começam a vibrar e ressoar as subjetividades, deixando as ordens, as significâncias, as interpretações de lado. Aqui, destaca-se que acompanhar a processualidade na cartografia não é uma etapa, ou segmento da pesquisa, e sim a própria pesquisa.

Transformando a paisagem que está sedimentada, o texto se movimenta num nomadismo que busca a singularidade e, por matérias instáveis (DELEUZE; GUATTARI, 2011), constitui para si uma orientação ao invés de organização: o guia é estar à espreita e detectar os signos (KASTRUP, 2015) da própria processualidade e situando-se "com o questionamento que ela contém e as problemáticas que ela suscita" (LANCRI, 2002, p. 20). Para tanto, inventam-se, fabricam-se e fabulam-se modos de fazer abandonando as inclinações pessoais, os juízos, as interpretações, as categorizações e as organizações. 


\section{Considerações finais}

Para produzir este texto, acompanhou-se um processo (KASTRUP, 2015) e, para tanto, inventou-se formas de dizer sobre as forças que este compôs. Conforme a investigação e a prática artística ganham consistência, novas necessidades artísticas e filosóficas surgem pelas porosidades que o território criará. No deslocar dos referenciais artísticos e teóricos, vibra o desejo de produzir uma prática artística da poética banal numa paisagem que possibilite encontros.

Ao adotar uma abordagem de pesquisa teórica filosófica para falar de uma prática artísticadocente, distribuíram-se afetos, dotando de potência as imanências. Um plano intensivo foi, aos poucos, sendo arrancado das relações que eram postas, "as forças intensivas subtendem as forças motrizes" (DELEUZE, 2011, p. 88). Compondo-a com as ações artísticas feitas pelo pesquisador (Prática Poética do Banal) e as suas referências artísticas (Allan Kaprow, Paulo Bruscky e Karina Dias), novos trajetos evocaram fugas das linguagens dominantes e de uma educação presa em modelos. 


\section{REFERÊNCIAS}

ANJOS, Moacir. O Ateliê como Arquivo. In: BIENAL DE SÃO PAULO, 26a 2004.

ARTAUD, Antonin. O teatro e seu duplo; tradução Teixeira Coelho. São Paulo: Martins Fontes, 2006.

BARROS, Laura Pozzana de; KASTRUP, Virgínia. Cartografar é acompanhar processos. In: PASSOS, Eduardo; KASTRUP, Virgínia; ESCÓSSIA, Liliana (orgs.). Pistas do método da cartografia:

Pesquisa-intervenção e produção de subjetividade. Porto Alegre: Sulina, 2015, p. 52-75.

BRITTO, Ludmila da Silva Ribeiro de. O Ateliê / Arquivo de Paulo Bruscky: Um acervo vasto de quase tudo. Revista Ohun, v. 5, p. 14-23, 2011.

CORAZZA, Sandra Mara. Notas para pensar as oficinas de transcriação (Os'T). In HEUSER, Ester Maria Dreher (Org.). Caderno de notas I: projeto, notas \& ressonâncias. Cuiabá: EdUFMT, 2011.

CORAZZA, Sandra Mara. Para artistar a educação: sem ensaio não há inspiração. In: CORAZZA, Sandra Mara. O que se transcrita em educação? Porto Alegre: UFRGS; Doisa, 2013. Cap.1, p.17-40.

DELEUZE, Gilles. Espinosa: filosofia prática. São Paulo: Escuta, 2002.

DELEUZE, Gilles. O que as crianças dizem. In: Crítica e clínica. Tradução de Peter Pál Pelbart. São Paulo: Editora 34, 2011. Cap. 9, p. 83-90.

DELEUZE, Gilles. Dois regimes de loucos: texto e entrevista (1975-1995). Tradução: Guilherme Ivo. São Paulo: Editora 34, 2016.

DELEUZE, Gilles. O que é o ato de criação? In: DELEUZE, Gilles. Dois regimes de loucos: texto e entrevista (1975-1995). Tradução: Guilherme Ivo. São Paulo: Editora 34, 2016. Cap.45, p. 332-343.

DELEUZE, Gilles; GUATTARI, Félix. O que é a Filosofia? Tradução: Bento Prado Jr. e Alberto Alonso Muñoz. São Paulo: Editora 34, 2010.

DELEUZE, Gilles; GUATTARI, Félix. Mil platôs. Capitalismo e esquizofrenia 2. vol. 1. Tradução de Ana Lúcia de Oliveira, Aurélio Guerra Neto e Celia Pinto Costa. São Paulo: Editora 34, 2011 a.

DELEUZE, Gilles; GUATTARI, Félix. Mil platôs. Capitalismo e esquizofrenia 2. vol. 2. Tradução de Ana Lúcia de Oliveira e Lúcia Cláudia Leão. São Paulo: Editora 34, 2011b.

DELEUZE, Gilles; GUATTARI, Félix. Mil platôs. Capitalismo e esquizofrenia 2. vol. 3. Tradução de Aurélio Guerra Neto, Ana Lúcia de Oliveira, Lúcia Cláudia Leão e Suely Rolnik. São Paulo: Editora 34, 2012a.

DELEUZE, Gilles; GUATTARI, Félix. Mil platôs. Capitalismo e esquizofrenia 2. vol. 4. Tradução de Suely Rolnik. São Paulo: Editora 34, 2012b.

DELEUZE, Gilles; GUATTARI, Félix. Mil platôs. Capitalismo e esquizofrenia 2. vol. 5. Tradução de Peter Pál Pelbart e Janice Caiafa. São Paulo: Editora 34, 2012c.

DELEUZE, Gilles; PARNET, Claire. O abecedário de Gilles Deleuze: transcrição integral do vídeo, para fins exclusivamente didáticos. Paris: Éditions Montparnasse, 1988. 
DIAS, Karina e Silva. A prática do banal, uma aspiração paisagística. In: 20 ANPAP - Subjetividade, Utopias e Fabulações, 2011, Rio de Janeiro. Anais do Encontro Nacional da ANPAP. Rio de Janeiro: UERJ, 2011. p. 3771-3783.

GUATTARI, Félix. Caosmose: um novo paradigma estético; tradução de Ana Lúcia de Oliveira e Lúcia Cláudia Leão. São Paulo: Editora 34, 2012.

LOPONTE, Luciana Gruppelli. Tudo isso que chamamos de formação estética: ressonâncias para a docência. Revista Brasileira de Educação. 2017, v. 22, n. 22, pp. 429-452.

KAPROW, Allan. A educação do an-artista parte I. Concinnitas - Revista do Instituto de Artes da UERJ, Rio de Janeiro, ano 4, n. 4, p. 216-227, mar. 2003.

KAPROW, Allan. A educação do an-artista. Parte II. Concinnitas - Revista do Instituto de Artes da UERJ. Rio de Janeiro, ano 5, n. 6, p. 167-181, julho 2004.

KAPROW, Allan. Como fazer um happening. 1966. (Tradução em português, editada para SEVERO, André), In: SEVERO, André; BERNARDES, Maria Helena (cur.), Horizonte Expandido, Santander Cultural, Porto Alegre, 2010.

KASTRUP, Virgínia; PASSOS, Eduardo. Cartografar é traçar um plano comum. Fractal, Rev. Psicol. 2013, vol. 25, n. 2, p. 263-280.

KASTRUP, Virgínia. O Funcionamento da Atenção no trabalho do cartógrafo. In: PASSOS, Eduardo; KASTRUP, Virgínia; ESCÓSSIA, Liliana (orgs.). Pistas do método da cartografia: Pesquisaintervenção e produção de subjetividade. Porto Alegre: Sulina, 2015, p. 32-51.

MACHADO, Roberto. Deleuze, a arte e a filosofia. Rio de Janeiro: Jorge Zahar Ed., 2009.

RAZÃO INADEQUADA. Deleuze - Do caos ao cais. Razão Inadequada, 2017. Disponível em: < https://razaoinadequada.com/2017/12/27/deleuze-do-caos-ao-cais/>. Acesso em: 11 OUT. 2020.

ROLNIK, Suely. Cartografia sentimental: transformações contemporâneas do desejo. Porto Alegre: Sulina; Editora da UFRGS, 2016.

ZOURABICHVILI, François. O Vocabulário de Deleuze; tradução André Telles. Rio de Janeiro: Relume Dumará: Sinergia: Ediouro, 2009. 